\title{
Rectifying neurologic diagnosis through autoantibodies
}

Tools that improve our ability to provide patients with a speedy and accurate diagnosis can come in many forms, and I have chosen several articles in this issue of $\mathrm{N} 2$ to highlight this point.

The 2017 McDonald diagnostic criteria for MS include modifications of the 2010 criteria to facilitate an earlier diagnosis of MS while preserving the accuracy of the previous criteria. Up to $10 \%$ of patients with MS have their first symptoms before the age of 18 years. However, MS diagnosis based on the baseline MRI obtained during the first attack of an acquired demyelinating syndrome (ADS) in children younger than 12 years or in those presenting with acute disseminated encephalomyelitis (ADEM) should be considered with caution because of the lower specificity and sensitivity of the McDonald 2010 criteria in these 2 groups. In the current issue of N2, Wong et al. ${ }^{1}$ compared the diagnostic accuracy of the 2017 and $2010 \mathrm{McD}$ onald criteria in children with $\mathrm{ADS}$ at first presentation paying particular attention to patients younger than 12 or presenting with ADEM. Among 164 patients, 110 (67\%) presented without encephalopathy and 54 (33\%) with encephalopathy or ADEM. Of the 110 ADS patients, $47 \%$ were diagnosed with clinically definite MS within a median follow-up of 4.5 years. The sensitivity was higher for the 2017 criteria than for the 2010 criteria ( $83 \%$ vs $49 \%$ ), but the specificity was lower (73\% vs $87 \%$ ). At baseline, 48 patients fulfilled the 2017 criteria and 27 patients fulfilled the 2010 criteria. For ADEM cases, 10\% fulfilled the 2017 criteria and $8 \%$ fulfilled the 2010 criteria. The authors conclude that the 2017 criteria are more sensitive than the 2010 criteria for predicting definite MS at baseline; these criteria can be applied in children younger than 12 years without encephalopathy, but not in children with ADEM. As the authors indicate, this study has several limitations related to the choice of brain and spinal MRI, inclusion of contrast or not, and the decision to include CSF testing for oligoclonal bands, which were left to the discretion of the treating physicians. However, the data suggest that the McDonald 2017 criteria perform well in children.

In another study, Patterson et al. ${ }^{2}$ describe 2 patients diagnosed with small-vessel primary CNS vasculitis who, in fact, had myelin oligodendrocyte glycoprotein (MOG) antibody-associated encephalitis. In both cases, the initial diagnosis was influenced by biopsy findings showing interstitial and perivascular lymphocytic infiltrates affecting but not confined to the vessel wall. As indicated by the authors, and the accompanying editorial comment, the presence of inflammatory cells in the vessel wall is sufficient for the diagnosis of medium- or large-sized vessel vasculitis; however, for small vessel vasculitis, the diagnostic criteria require evidence of vessel damage such as fibrin deposition or necrosis, which were absent in both patients. In these patients, an earlier diagnosis of MOG-associated encephalitis would have prevented the brain biopsy. Additionally, important implications were illustrated by one of the patients, who despite treatment with cyclophosphamide (aimed at the diagnosis of vasculitis) was having clinical relapses; these resolved after the diagnosis of MOG antibody-associated encephalitis was made and a B-cell depletion therapy was implemented. The authors indicate that there are previous reports of patients with CNS small vessel

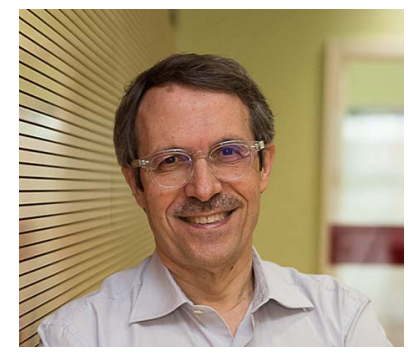

MORE ONLINE

() Editor Summary

NPub.org/N2/edsum 
vasculitis who later developed symptoms compatible with MOG-antibody-associated syndromes (myelitis or optic neuritis), suggesting that this diagnostic confusion may not be unusual.

Autoimmune episodic ataxia (EA) has been reported in patients with Caspr2 antibody-associated encephalitis. ${ }^{3}$ In the current issue, Drs. Lopez Chiriboga and Pittock ${ }^{4}$ report a 64-year-old man who developed cognitive dysfunction and seizures, followed by episodes of transient speech and gait disturbances lasting several minutes and occurring multiple times per day. The brain MRI was normal, and CSF analysis showed only elevated protein concentration. The diagnosis of Caspr2 antibody-associated encephalitis led to treatment with immunotherapy and dramatic improvement of symptoms. Overall, considering this and a previous report of 6 patients, EA should be added to the list of paroxysmal neurologic symptoms caused by autoantibodies, such as faciobrachial dystonic seizures and anti-LGI1 antibodies, and orthostatic myoclonus and anti-Caspr2 antibodies. In contrast to faciobrachial dystonic seizures that usually precede limbic encephalitis, Caspr2-antibody associated EA more often develops after, or concomitantly with, limbic encephalitis. The similarities between autoimmune and genetic EA type I, caused by mutations of KCNA1 that codes for the voltage-gated potassium channel Kv1.1 and interacts with Caspr2, have been previously noted. One suspects that if a "forme fruste" of Caspr2-antibody associated encephalitis manifests as isolated or predominant EA, the diagnosis may be missed.

Miranda-Acuña et al. $^{5}$ report the favorable outcome of a patient with neuromyelitis optica (NMO) treated during pregnancy with rituximab. The patient conceived 3 months after the last dose of rituximab and received another infusion of $1,000 \mathrm{mg}$ at 24 weeks of pregnancy, maintaining the $\mathrm{CD} 19^{+}$count $<1 \%$. The newborn APGAR score was normal, and the $\mathrm{CD} 19^{+}$cell count was $1 \%$ at birth; 2 months later, the infant's $\mathrm{CD} 19^{+}$count was $23 \%$. Previous reports have explored the potential complications of rituximab during pregnancy ${ }^{6,7}$; however, systematic reviews are often confounded by limited available information or concomitant use of drugs with potential effects on pregnancy. Therefore, reporting detailed information of pregnant patients affected with severe diseases that may benefit from rituximab (e.g., NMO, anti-NMDA receptor encephalitis) is strongly encouraged.

In addition to these studies, the March issue of $\mathrm{N} 2$ contains an infographic summary of the study "Characterization of MS phenotypes using MRI and miRNA profiles" by Hemond et al., ${ }^{8}$ as well as other interesting articles that I hope will catch your attention.

\section{Study funding}

No targeted funding.

\section{Disclosure}

J. Dalmau is the editor of Neurology: Neuroimmunology \& Neuroinflammation, is on the editorial board for Neurology UpToDate; holds patents for and receives royalties from Ma2 autoantibody test, NMDA receptor autoantibody test, $\mathrm{GABA}(\mathrm{B})$ receptor autoantibody test, $\mathrm{GABA}(\mathrm{A})$ receptor autoantibody test, DPPX autoantibody test, and IgLON5 autoantibody test; and receives research support from Euroimmun, NIH, Fundació CELLEX, Instituto Carlos III (CIBERER, and Fondo de Investigaciones Sanitarias). Full disclosure form information provided by the authors is available with the full text of this article at Neurology.org/NN.

\section{Publication history}

Received by Neurology: Neuroimmunology \& Neuroinflammation January 4, 2019. Accepted in final form January 4, 2019.

\section{References}

1. Wong YYM, Louk de Mol C, van der Vuurst de Vries RM, et al. Real world validation of the $2017 \mathrm{McD}$ onald criteria for pediatric multiple sclerosis. Neurol Neuroimmunol Neuroinflamm 2019;6:e528. doi: 10.1212/NXI.0000000000000528.

2. Patterson K, Iglesias E, Nasrallah M, et al. Anti-MOG encephalitis mimicking small vessel CNS vasculitis. Neurol Neuroimmunol Neuroinflamm 2019;6:e538. doi 10.1212/NXI.0000000000000538.

3. Joubert B, Gobert F, Thomas L, et al. Autoimmune episodic ataxia in patients with anti-CASPR2 antibody-associated encephalitis. Neurol Neuroimmunol Neuroinflamm 2017;4:e371. doi: 10.1212/NXI.0000000000000371.

4. Lopez-Chiriboga AS, Pittock S. Episodic ataxia in CASPR-2 autoimmunity. Neurol Neuroimmunol Neuroinflamm 2019;6:e536. doi: 10.1212/NXI.0000000000000536.

5. Miranda-Acuña J, Rivas-Rodriguez E, Levy M, et al. Rituximab during pregnancy in neuromyelitis optica: A case report. Neurol Neuroimmunol Neuroinflamm 2019;6:e542. doi: 10.1212/NXI.0000000000000542.

6. Das G, Damotte V, Gelfand JM, et al. Rituximab before and during pregnancy: a systematic review, and a case series in MS and NMOSD. Neurol Neuroimmunol Neuroinflamm 2018;5:e453. doi: 10.1212/NXI.0000000000000453.

7. Chakravarty EF, Murray ER, Kelman A, Farmer P. Pregnancy outcomes after maternal exposure to rituximab. Blood 2011;117:1499-1506.

8. Hemond CC, Healy BC, Tauhid S, et al. MRI phenotypes in MS: Longitudinal changes and miRNA signatures. Neurol Neuroimmunol Neuroinflamm 2019;6:e530. doi: $10.1212 /$ NXI.0000000000000530. 


\title{
Neurology \\ Neuroimmunology \& Neuroinflammation
}

\author{
Rectifying neurologic diagnosis through autoantibodies \\ Josep Dalmau \\ Neurol Neuroimmunol Neuroinflamm 2019;6; \\ DOI 10.1212/NXI.0000000000000540
}

This information is current as of February 15, 2019

\section{Updated Information \& Services}

References

Permissions \& Licensing

Reprints including high resolution figures, can be found at:

http://nn.neurology.org/content/6/2/e540.full.html

This article cites 8 articles, 4 of which you can access for free at: http://nn.neurology.org/content/6/2/e540.full.html\#\#ref-list-1

Information about reproducing this article in parts (figures,tables) or in its entirety can be found online at:

http://nn.neurology.org/misc/about.xhtml\#permissions

Information about ordering reprints can be found online: http://nn.neurology.org/misc/addir.xhtml\#reprintsus

Neurol Neuroimmunol Neuroinflamm is an official journal of the American Academy of Neurology.

Published since April 2014, it is an open-access, online-only, continuous publication journal. Copyright

Copyright $\odot 2019$ The Author(s). Published by Wolters Kluwer Health, Inc. on behalf of the American Academy of Neurology.. All rights reserved. Online ISSN: 2332-7812.

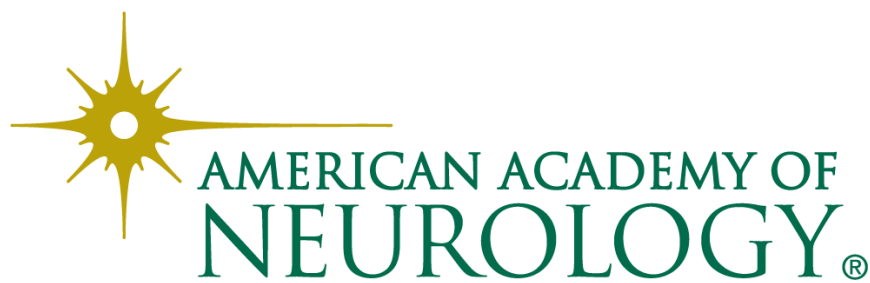

